\title{
Serum Neopterin Level in Children with Attention Deficit Hyperactivity Disorder and Autistic Spectrum Disorder
}

\author{
Abd El-Ghaffar HM (1), Dawoud ME (2), Abdelghaffar NK (3), Ahmed HH (4) \\ (1) Prof. Hadeer Mahmoud Gamal El-Deen Abd El-Ghaffar professor of Pediatrics, Faculty of \\ Medicine, Fayoum University. \\ (2) Dr. Mariam Ehab Dawoud Lecturer of Psychiatry Faculty of Medicine, Fayoum University. \\ (3) Dr. Noha Khalifa Abdelghaffar Assistant professor of clinical pathology, Faculty of \\ Medicine, Fayoum University. \\ (4) M.M.B.C.H Department of Pediatrics, Faculty of Medicine, Fayoum University.
}

Corresponding author: prof. Hadeer Mahmoud Gamal El-Deen

E-mail address: Abeerreda23588@gmail.com

Tel: 01099858523

\section{ABSTRACT}

Various genetic, psychological, social, environmental and biochemical factors are thought to be involved in the etiopathogenesis of ADHD and ASD.

Central nervous system and immune system are systems which are in interaction with each other. The cellular immunity may contribute to the development of the disorder via affecting the brain cell functions.

High levels of neopterin are a wellestablished marker of immune activation, consistent with heightened cell-mediated immunity.

We evaluated serum Neopterin as a marker of inflammation and we found no statistically significant difference in serum Neopterin level between ADHD group , ASD group and control group .Also no statistically significant difference between severity of both ASD and ADHD and Neopterin level.

KEY WORDS: ASD, ADHD, Neopterin.

\section{INTRODUCTION}

Attention defici//hyperactivity disorder (ADHD) is one of the most common childhood neuropsychiatric disorders, whose core symptoms are inattention, hyperactivity and impulsivity [1].

ASD is characterized by a significant impairment in social interaction and communication and a markedly restricted repertoire of activity and interests. Although the etiology is unknown, immune system dysfunction has been hypothesized to contribute to the pathophysiology [2]. 
High levels of neopterin are a wellestablished marker of immune activation, consistent with heightened cell-mediated immunity.[3]

Increased serum neopterin levels have also been found in neuropsychiatric disorders in which inflammatory processes might be activated, such as ASD and Tourette's syndrome[4].

\section{PATIENTS AND METHODS}

This study was a cross sectional case-control study. Participants included in this study were 25 patients with ADHD diagnosed according to the DSM-5 criteria, and 25 patients with ASD diagnosed according to DSM-5 from the Neuro pediatric and psychiatric outpatient clinics, Fayoum University Hospitals as well as 25 healthy controls matched in age, gender.Patients with a psychiatric, neurometabolic ,Neuro degenerative and neurocutaneous diseases were excluded, as were patients with a history of chronic systemic diseases, such as endocrinologic and allergic diseases. Patients who previously had used psychotropic drugs within last 6 months were excluded as well. Blood sampling

Blood samples of participants were collected between 9:00 AM and 12:00 AM.Serum neopterin levels were measured by using commercially enzyme linked immuno- assay (ELISA) kit.

\section{RESULTS}

This study releaved that there is no statistically significant difference between mean Neopterin level and in control group and Patients group (Table (1)).

In our study, No statistically significant difference found between mean Neopterin level in ADHD subtypes ( $p$ value $=0.618$ ) .

There was no statistically significant difference in mean Neopterin level in relation with severity of ASD symptoms ( $\mathrm{p}$ value $=0.769$ ). 


\begin{tabular}{|c|c|c|c|c|}
\hline & $\begin{array}{l}\text { Control } \\
(N=25)\end{array}$ & $\begin{array}{c}\text { ADHD } \\
(N=25)\end{array}$ & $\begin{array}{c}\text { ASD } \\
(\mathrm{N}=25)\end{array}$ & P-value \\
\hline \multicolumn{5}{|c|}{ Neopterin level } \\
\hline Mean & 7.7 & 7.7 & 9.4 & \multirow{5}{*}{0.758} \\
\hline SD & 11.4 & 11.4 & 13.2 & \\
\hline Median & 2.4 & 2.3 & 1.7 & \\
\hline Minimum & 0.5 & 0.3 & 0.3 & \\
\hline Maximum & 40.1 & 44.9 & 42.3 & \\
\hline
\end{tabular}

Table (1) Neopterin level in control group and patient groups

\section{DISCUSSION}

This study points to an immunological dimension of ADHD and ASD. In this study, we investigated the serum neopterin levels in child patients with ADHD and ASD .

This study releaved that there is No statistically significant difference regarding serum Neopterin level between control group and patients group.

In our study, No statistically significant difference found between mean Neopterin level in ADHD subtypes ( $\mathrm{p}$ value $=0.618$ ). This is consistent with Ceylan et al.,2014 who found no significant differences in neopterin levels among the subtypes of ADHD.[5]

In our study ,There was no statistically significant difference in mean Neopterin level in relation with severity of ASD symptoms ( $p$ value $=0.769$ ).

In our study, there is no statistically significant difference in
Neopterin level between ASD group and ADHD group.

\section{CONCLUSION}

Autistic spectrum disorders (ASD) and Attention deficit/hyperactivity disorder (ADHD) are the most frequently occurring neuropsychiatric disorders in childhood with an etiology that is not fully understood. Whether elevated plasma neopterin could be used as a diagnostic tool for detection of ASD and ADHD in our sample needs further research.

\section{REFERENCES}

[1] American Psychiatric Association, (2013). Diagnostic and statistical manual of mental disorders 5th edition.

[2] Warren RP, Margaretten NC, Pace

$\mathrm{NC}$, Foster A: Immune abnor- malities in 
patients with autism. J Autism Dev Disord 1986; 16: 189-197

[3] Berdowska, A., Zwirska-Korczala, K., 2001. Neopterin measurement in clinical diagnosis, journal of clinical pharmacy and therapeutics. J. Clin. Pharm. Ther. 26 (5), 319-329.

[4] Bodur S, Ceylon MF , Iseri E, Sener S \& Yucel AA,(2013)Serum neopterin levels in patients with autism
,https://doi.org/10.1179/2047387713Y.00 00000029

[5] Ceylan M F , Uneri O S, Guney E, Ergin M, Alisik M, Goker Z, Dinc G S, Kara F K, Erel O.(2014).Increased levels of serum neopterin in attention deficit/hyperactivity disorder (ADHD). Journal of Neuroimmunology 273 (2014) 111-114 http://dx.doi.org/10.1016/j.jneuroim.2014. 06.002 